\title{
Antimicrobial and antioxidant activities of Kingiodendron pinnatum (DC.) Harms and Humboldtia brunonis Wallich: endemic plants of the Western Ghats of India
}

\author{
Sana Sheik and K.R. Chandrashekar ${ }^{*}$ \\ Department of Applied Botany, Mangalore University, Mangalagangothri-574199, Konaje, India.
}

\begin{abstract}
The leaf and stem extracts of two endemic plants, Kingiodendron pinnatum (DC.) Harms and Humboldtia brunonis Wallich of the family Fabaceae were subjected to phytochemical analysis, antimicrobial and antioxidant assay. Phytochemicals such as phenols, flavonoids, tannins, glycosides and terpenes were present in both plants. The antibacterial and antifungal activity assays were carried out using the disc diffusion method. Antioxidant activity was carried out using DPPH radical scavenging and reducing power assays with ascorbic acid as the standard. The extracts inhibited six bacterial strains and one fungal strain. Among the solvent extracts, the methanol extract was the most effective against the tested microorganisms and it also exhibited the highest antioxidant activity. Total phenols and flavonoids were determined using the Folin-Ciocalteau and aluminium chloride methods and correlated with the antioxidant activity.
\end{abstract}

Keywords: Antimicrobial, antioxidant activity, Kingiodendron pinnatum (DC.), Humboldtia brunonis Wallich.

\section{INTRODUCTION}

Medicinal plants play an important role in promoting good health, especially in the developing countries (Oudhia \& Tripathi, 1999). The medicinal value of plants are attributed to the chemically active substances that produce a definite physiological action on the human body. Several biologically active substances found in plants, including phenolic compounds (flavonoids, phenolic acids), sugars, vitamins, saponins, ethereal oils, polyunsaturated fatty acids, phospholipids, enzymes, amino acids etc., are known to possess antioxidant properties. Saponins possess specific chemical, physical and biological properties that make them useful as medicines. Phenols and flavonoids are potent antioxidants or free radical scavengers, which prevents oxidative cell damage and have strong anti-cancer activity (Okwu \& Josiah, 2006). Hence, the development and utilization of more effective antioxidants of natural origin is desired (Arunachalam, 2011). Many plants have been used for their antimicrobial activity and the increasing microbial resistance to antibiotics is prompting a resurgence in the research into antimicrobial activity of plant derivatives against resistant strains (Alviano \& Alviano, 2009).

Fabaceae, the third largest family of angiosperms with approximately 730 genera and over 19400 species worldwide includes the plants commonly known as legumes (Wojciechowski et al., 2004). Several types of alkaloids, non-protein amino acids, amines, flavonoids, isoflavonoids, coumarins, phenylpropanoids, anthraquinones, di-, sesqui- and triterpenes, cyanogenic glycosides, protease inhibitors and lectins have been described from this family (Wink, 2003). Some of the endemic plants of the Western Ghats have been reported to possess antimicrobial (Hidayathulla et al., 2011; Shetty et al., 2011; Arumugasamy, 2012) and antioxidant activities (Sukesh et al., 2011; Nair et al., 2012). Humboldtia brunonis and Kingiodendron pinnatum, well known endemic plants of the Western Ghats in India belong to this family. H. brunonis Wallich, a dominant myrmecophyte, commonly known as 'hasige mara' is endemic to the biodiversity hotspot of the South Western Ghats of India (Pascal, 1988). In traditional medicine this plant is used to treat menstrual problems. $K$. pinnatum (DC.) Harms known as the 'Malabar mahogany', a vulnerable and endangered medicinal plant is used in curing sores of elephants. The oleo-gum-resin of this plant 
species is used in gonorrhoea and catarrhal conditions of genito-urinary and respiratory tracts (Komal et al., 2011).

The paper describes the extraction and evaluation of phytochemicals from $K$. pinnatum and $H$. brunonis, and the assessment of antimicrobial and antioxidant properties of the extracts.

\section{METHODS AND MATERIALS}

\section{Collection of plant material}

The fresh leaves and stems of $K$. pinnatum (DC.) Harms and H. brunonis Wallich were collected from the Charmady region of the Western Ghats. The leaves and stems were shade dried, powdered and stored in air-tight polythene bags until use.

\section{Preparation of the extract}

Fifty grams of dried and powdered samples of both leaf and stem were soxhlet extracted using methanol and ethyl acetate as solvents. The samples were concentrated using a rotary evaporator. An aqueous extract was obtained by boiling $50 \mathrm{~g}$ of the dried and powdered sample for $8 \mathrm{~h}$ in a water bath and the solution was filtered through six layers of muslin cloth. The supernatant was collected and evaporated to dryness. All the extracts were stored at $4{ }^{\circ} \mathrm{C}$ until use.

\section{Phytochemical analysis}

The extracts were screened for the presence of the following phytochemicals - alkaloids (Hagers test, Wagners test, Mayers test, Dragendorff's test), flavonoids (Shinodas test), steroids (Libermann- Burchard test and Salkowski test), phenols ( $\mathrm{FeCl}_{3}$ test), tannins (lead acetate test), saponins (foam test), glycosides (Molisch's test, sodium hydroxide test) and resins (turbidity test) (Dey \& Harborne, 1987).

Determination of total phenolic content: The total phenolic content was measured by the Folin-Ciocalteau method (Taga et al., 1984). A known aliquot from the stock sample $(10 \mathrm{mg} / \mathrm{mL})$ was mixed with $2.0 \mathrm{~mL}$ of $2 \% \mathrm{Na}_{2} \mathrm{CO}_{3}$ and allowed to stand for $2 \mathrm{~min}$ at room temperature. Then $100 \mu \mathrm{L}$ of $50 \%$ Folin Ciocalteau's phenol reagent was added. After incubation for $30 \mathrm{~min}$ at room temperature in darkness, the absorbance was read at $725 \mathrm{~nm}$ using a spectrophotometer. The total phenolic contents of the samples were expressed as mg gallic acid equivalent per gram of extract (mg GAE/g).
Determination of flavonoid content: Total flavonoid content was measured by the aluminium chloride method (Zhishen et al., 1999). A known volume of each extract was made up to $4 \mathrm{~mL}$ with distilled water and $0.3 \mathrm{~mL}$ of $\mathrm{NaNO}_{2}$ (1:20) was added. After $5 \mathrm{~min}, 0.3 \mathrm{~mL}$ of $10 \%$ $\mathrm{AlCl}_{3} \cdot \mathrm{H}_{2} \mathrm{O}$ solution was added and after $6 \mathrm{~min}, 2 \mathrm{~mL}$ of $1 \mathrm{M} \mathrm{NaOH}$ solution was added. The total volume was made up to $10 \mathrm{~mL}$ using distilled water. The absorbance against the blank was determined at $510 \mathrm{~nm}$. Results were expressed as $\mathrm{mg}$ quercetin equivalent per gram of extract (mg QE /g).

\section{Antimicrobial activity}

The microorganisms used for the microbial sensitivity assay were Gram positive Staphylococcus aureus (NCIM 2079), Bacillus subtilis (ATCC 6633) and Gram negative Escherichia coli (NCIM 2931), Pseudomonas aeruginosa (NCIM 2200), Klebsiella pneumoniae (NCIM 2957) and Proteus vulgaris (NCIM 2813) procured from the National Chemical Laboratory, Pune, India. Two of the fungal strains Aspergillus niger (MTCC 1344) and Candida albicans (MTCC 227) were obtained from IMTECH, Chandigarh, India and Trichoderma viridae from the Plant Pathology Laboratory, CPCRI, Kasargod, India. The bacterial strains were maintained in nutrient agar slants and the fungal strains on potato dextrose agar slants at $4{ }^{\circ} \mathrm{C}$ in the refrigerator.

Antibacterial and antifungal assays were carried out using the disc diffusion method (Vardar-Unlu et al., 2003). For the in vitro antibacterial activity, $200 \mu \mathrm{L}$ of overnight grown culture of each bacterium was dispensed in $20 \mathrm{~mL}$ of sterile nutrient broth and incubated $\left(37^{\circ} \mathrm{C}\right)$ for $4-5 \mathrm{hrs}$ to standardize the culture to $10^{-5} \mathrm{CFU} / \mathrm{mL}$. From the $24 \mathrm{hrs}$ old bacterial culture $0.1 \mathrm{~mL}\left(10^{-5} \mathrm{CFU}\right.$ $/ \mathrm{mL}$ ) was placed on Muller Hinton agar medium (Shetty et al., 2011) and spread throughout the plate by spread plate technique. The dried crude extract $(35 \mathrm{mg}$ ) was dissolved in $1 \mathrm{~mL}$ of dimethyl sulphoxide (DMSO) and $25 \mu \mathrm{L}$ of the respective solvent extracts were added to the sterile discs (6 mm diameter purchased from HIMEDIA Laboratories, India) individually and aseptically. The discs were then transferred to the inoculated petri plates.

The antifungal activity was assayed by fungal inoculation on to potato dextrose agar (PDA) medium containing the discs pre-impregnated with the plant extracts. Fungal inoculum was prepared by taking $5-8$ colonies of the fresh fungal strain from the petri dish and suspending in $5 \mathrm{~mL}$ of sterile distilled water. Hundred microlitres of this fungal inoculum was dispensed in $20 \mathrm{~mL}$ of sterile PDA medium. The discs impregnated 
with the crude extracts were prepared as described above for the antimicrobial assay. The cultures were incubated for 2 days in case of Candida albicans and $4-5$ days for the other two fungi.

Antimicrobial activity was recorded by measuring the diameter of the zone of inhibition. Streptomycin and nystatin (HIMEDIA) were used as positive standards against the bacterial and fungal strains, respectively.

\section{Antioxidant Assay}

DPPH radical scavenging assay (Liyana et al., 2005): A solution of DPPH $(0.135 \mathrm{mM})$ in methanol was prepared and $1 \mathrm{~mL}$ of this solution was mixed with $1 \mathrm{~mL}$ of varying concentrations of the extracts. The reaction mixture was vortexed thoroughly and left in the dark at room temperature for $30 \mathrm{~min}$. The absorbance of the mixture was measured at $517 \mathrm{~nm}$ using a SYSTRONICS spectrophotometer 166 with ascorbic acid as the standard. The ability to scavenge DPPH radicals was calculated as:

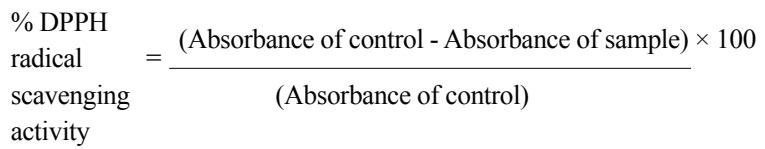

The activity was expressed as $50 \%$ inhibitory concentration $\left(\mathrm{IC}_{50}\right)$ based on the percentage of DPPH radicals scavenged.

Reducing power assay (Oyaizu, 1986): Hundred microlitres of the extract from the stock solution $(10 \mathrm{mg} /$ $\mathrm{mL})$ was mixed with phosphate buffer $(2.5 \mathrm{~mL}, 0.2 \mathrm{M}$, $\mathrm{pH}$ 6.6) and $1 \%$ potassium ferricyanide $(2.5 \mathrm{~mL})$. The mixture was incubated at $50^{\circ} \mathrm{C}$ for $20 \mathrm{~min}, 2.5 \mathrm{~mL}$ of $10 \%$ trichloroacetic acid added and centrifuged at $3000 \mathrm{rpm}$ for $10 \mathrm{~min}$. The supernatant $(2.5 \mathrm{~mL})$ was mixed with distilled water $(2.5 \mathrm{~mL})$ and a freshly prepared $\mathrm{FeCl}_{3}$ solution $(0.5 \mathrm{~mL}, 0.1 \%)$. The absorbance was measured at $700 \mathrm{~nm}$. The reducing power was expressed as ascorbic acid equivalent (AAE) milligram per gram of extract. All the experiments were triplicated.

\section{Statistical analysis}

Statistical analysis was carried out using Graph Pad Prism Software and MS excel. Correlation was used where appropriate and the differences between extract activities were compared using one way ANOVA with Bonferroni test. Differences were considered statistically significant when $\mathrm{p}<0.05$.

\section{RESULTS}

The percentage yield of $K$. pinnatum leaf extract from methanol, water and ethyl acetate was $16.64,7.18$ and $6.57 \%$, respectively, and from the stem extract it was $8.45,18.17$ and $3.48 \%$, respectively. The highest yield of $16.64 \%$ was observed in the methanolic leaf extract of $K$. pinnatum and the lowest $(3.48 \%)$ in the ethyl acetate extract of the stem. The percentage yield of $H$. brunonis leaf extract obtained from methanol, water and ethyl acetate was $11.06,10.62$ and $10.95 \%$, and from the stem extract it was 5.22, 3.29 and $3.69 \%$, correspondingly. Preliminary phytochemical screening revealed the presence of phenols, flavonoids, tannins and glycosides in all the extracts from both plants. Alkaloids were absent whilst saponins and resins were reported only in the leaf extracts of $K$. pinnatum (Table 1).

The highest antibacterial activity was exhibited by the methanol leaf extract and ethyl acetate leaf extract of $K$. pinnatum against Staphylococcus aureus $(17.16 \pm$ 0.35 and $16.86 \pm 0.05 \mathrm{~mm})$. The methanol leaf extract of $H$. brunonis and ethyl acetate leaf extract of $K$. pinnatum

Table 1: Results of phytochemical screening of Kingiodendron pinnatum and Humboldtia brunonis

\begin{tabular}{lcccccccccccc}
\hline & KLM & HLM & KSM & HSM & KLW & HLW & KSW & HSW & KLE & HLE & KSE & HSE \\
\hline Phenols & + & + & + & + & + & + & + & + & + & + & + & + \\
Flavonoids & + & + & + & + & + & + & + & + & + & + & + & + \\
Tannins & + & + & + & + & + & + & + & + & + & + & + & + \\
Saponins & + & - & - & - & + & - & - & - & - & - & - & - \\
Alkaloids & - & - & - & - & - & - & - & - & - & - & - & - \\
Glycosides & + & + & + & + & + & + & + & + & + & + & + & + \\
Steroids & + & + & + & + & - & + & - & + & + & + & + & + \\
Resins & + & - & + & - & - & - & - & - & - & - & - & - \\
\hline
\end{tabular}

+ Detected; - Not detected; $\mathrm{K}=$ Kingiodendron pinnatum $; \mathrm{H}=$ Humboldtia brunonis $; \mathrm{L}=\mathrm{Leaf} ; \mathrm{S}=\mathrm{Stem}$; $\mathrm{M}=$ Methanol; $\mathrm{E}=$ Ethyl acetate; $\mathrm{W}=$ Water 
Table 2: Antimicrobial activity of the extracts of Kingiodendron pinnatum and Humboldtia brunonis

\begin{tabular}{|c|c|c|c|c|c|c|c|c|c|}
\hline \multirow[t]{2}{*}{ Extract } & \multicolumn{9}{|c|}{ Zone of inhibition (diameter in $\mathrm{mm}$ ) } \\
\hline & TV & $\mathrm{AN}$ & $\mathrm{CA}$ & BS & SA & $\mathrm{KP}$ & $\mathrm{EC}$ & $\mathrm{PA}$ & PV \\
\hline HML & - & - & $26 \pm 0.3^{a}$ & $16.66 \pm 0.15^{a}$ & $14^{\mathrm{a}}$ & $14.33 \pm 0.57^{b}$ & $12.33 \pm 0.57^{b}$ & $11.66 \pm 0.5^{\mathrm{ab}}$ & $11.96 \pm 0.05^{b}$ \\
\hline HWL & - & - & $15 \pm 0.2^{b}$ & $13.56 \pm 0.57^{b c}$ & $12.33 \pm 0.57^{b}$ & $10.33 \pm 0.57^{a}$ & $8.33 \pm 0.57^{\mathrm{a}}$ & $9.00 \pm 0.00^{\mathrm{c}}$ & $8.63 \pm 0.55^{\mathrm{c}}$ \\
\hline HEL & - & - & $20 \pm 0.57^{\mathrm{c}}$ & $15.86 \pm 0.11^{\mathrm{a}}$ & $13.43 \pm 0.47^{b c}$ & $11.33 \pm 0.57^{\mathrm{a}}$ & $8.56 \pm 0.85^{\mathrm{a}}$ & $11.06 \pm 0.11^{\mathrm{a}}$ & $10.70 \pm 0.51^{b}$ \\
\hline HMS & - & - & $25 \pm 0.25^{\text {a }}$ & $14.33 \pm 0.30^{b}$ & $12.50 \pm 0.43^{b}$ & $11^{\text {a }}$ & - & $12.53 \pm 0.30^{\mathrm{ab}}$ & $11.13 \pm 0.15^{b}$ \\
\hline HWS & - & - & $14.8 \pm 0.46^{b}$ & $12.56 \pm 0.15^{\mathrm{c}}$ & $9.06 \pm 0.11^{\mathrm{d}}$ & $7.03 \pm 0.05^{c}$ & - & $9.00 \pm 0.00^{\mathrm{c}}$ & $10.20 \pm 0.26^{b}$ \\
\hline HES & - & - & $20 \pm 0.00^{\mathrm{c}}$ & $12.80 \pm 0.2^{\mathrm{c}}$ & $11.16 \pm 0.55^{\mathrm{e}}$ & $10.23 \pm 0.40^{a}$ & - & $11.10 \pm 0.17^{\mathrm{a}}$ & $10.06 \pm 0.11^{b}$ \\
\hline KML & - & - & $28 \pm 0.3$ & $16.30 \pm 0.52^{a}$ & $17.16 \pm 0.35^{\mathrm{a}}$ & $15.50 \pm 0.6^{\mathrm{a}}$ & $15.76 \pm 0.87^{\mathrm{c}}$ & $13.33 \pm 0.57^{b}$ & $14.86 \pm 0.90^{\mathrm{a}}$ \\
\hline KEL & - & - & $20 \pm 0.2^{b}$ & $15.46 \pm 0.37^{\mathrm{a}}$ & $16.86 \pm 0.05^{\mathrm{a}}$ & $13.33 \pm 0.57^{\mathrm{b}}$ & $14.30 \pm 0.69^{\mathrm{c}}$ & $11.66 \pm 0.57^{\mathrm{a}}$ & $14.66 \pm 0.41^{a}$ \\
\hline KWL & - & - & $15^{\mathrm{c}}$ & $14.13 \pm 0.49^{b}$ & $14.86 \pm 0.11^{\mathrm{c}}$ & $14.33 \pm 0.57^{b}$ & $11.87 \pm 0.15^{b}$ & $10.13 \pm 0.6^{\mathrm{ac}}$ & $10.33 \pm 0.57^{b}$ \\
\hline KMS & - & - & $20 \pm 0.25^{b}$ & $13.56 \pm 0.32^{b c}$ & $12.70 \pm 0.1^{\mathrm{b}}$ & $10.66 \pm 0.57^{a}$ & $11.56 \pm 0.58^{b}$ & $10.00 \pm 0.00 a$ & $10.90 \pm 0.1^{b}$ \\
\hline KES & - & - & $14.8 \pm 0.46^{\mathrm{c}}$ & $12.66 \pm 0.15^{\mathrm{c}}$ & $11.20 \pm 0.51^{\mathrm{e}}$ & $7^{c}$ & $9.63 \pm 0.63 \mathrm{ad}$ & $10.00 \pm 0.00 a c$ & $9.06 \pm 0.11^{\mathrm{c}}$ \\
\hline KWS & - & - & $20 \pm 0.00^{b}$ & $10.23 \pm 0.15$ & $9.33 \pm 0.57^{\mathrm{d}}$ & $10.66 \pm 0.57^{a}$ & $10.16 \pm 0.47 \mathrm{bd}$ & $9.33 \pm 0.57 \mathrm{ac}$ & $9.96 \pm 0.05 \mathrm{bc}$ \\
\hline \multicolumn{10}{|l|}{ Strepto- } \\
\hline mycin & & & & $22.16 \pm 0.37$ & $25.53 \pm 0.32$ & $24.1 \pm 0.1$ & $19.13 \pm 0.20$ & $20.63 \pm 0.15$ & $30.10 \pm 0.1$ \\
\hline \multicolumn{10}{|l|}{$10 \mu \mathrm{g} / \mathrm{mL}$} \\
\hline Nystatin & 16.23 & 18.9 & $25.23 \pm 0.20^{\mathrm{a}}$ & & & & & & \\
\hline $10 \mu \mathrm{g} / \mathrm{mL}$ & \pm 0.25 & \pm 0.32 & & & & & & & \\
\hline
\end{tabular}

Results with the same letter in each column are not significant $\mathrm{K}=$ Kingiodendron pinnatum $; \mathrm{H}=$ Humboldtia brunonis; $\mathrm{TV}$ - Trichoderma viridae; AN - Aspergillus niger; CA - Candida albicans; BS - Bacillus subtilis; SA - Staphylococcus aureus; KP - Kliebsiella pneumoniae; EC - Escherichia coli; PA - Pseudomonas aeruginosa; PV - Proteus vulgaris. L- Leaf; S - Stem; M - Methanol; E - Ethyl acetate; W - Water; - no activity

Table 3: Antioxidant activity, phenols, and flavonoids- of Kingiodendron pinnatum and Humboldtia brunonis

\begin{tabular}{|c|c|c|c|c|}
\hline Extracts & $\begin{array}{l}\text { Phenols } \\
\text { mg gallic acid } \\
\text { equivalent/g }\end{array}$ & $\begin{array}{l}\text { Flavonoids } \\
\text { mg quercetin } \\
\text { equivalent/g }\end{array}$ & DPPH-IC ${ }_{50}$ & $\begin{array}{l}\text { Reducing power } \\
\text { mg ascorbic acid } \\
\text { equivalent/g }\end{array}$ \\
\hline AA & & & $6.53 \pm 0.11^{a}$ & \\
\hline HLM & $189.51 \pm 0.32^{d}$ & $60.43 \pm 0.79$ & $7.66 \pm 0.11^{\mathrm{a}}$ & $338.69 \pm 1.54$ \\
\hline HLE & $80.99 \pm 0.21^{\mathrm{c}}$ & $34.45 \pm 1.21 \mathrm{ab}$ & $14.00 \pm 1^{\mathrm{a}}$ & $168.42 \pm 2.31^{\mathrm{a}}$ \\
\hline HLW & $40 \pm 0.8^{a}$ & $13.51^{\mathrm{c}}$ & $37.33 \pm 4.16^{b}$ & $140.20 \pm 4.65^{b}$ \\
\hline HSM & $68.79 \pm 0.85^{b}$ & $43.20 \pm 1.99^{\mathrm{a}}$ & $15.06 \pm 0.80^{\mathrm{a}}$ & $160.85 \pm 2.31^{\mathrm{a}}$ \\
\hline HSE & $61.57 \pm 0.18^{b}$ & $29.68 \pm 1.65^{b}$ & $31.33 \pm 3.21^{b}$ & $144.72 \pm 3.80^{b}$ \\
\hline HSW & $32.58 \pm 0.08^{a}$ & $14.01 \pm 0.86^{\mathrm{c}}$ & $38.00 \pm 3.46^{b}$ & $138.16 \pm 0.87^{b}$ \\
\hline KLM & $360.68 \pm 0.15$ & $122.46 \pm 2.10$ & $7.20 \pm 0.2^{\mathrm{a}}$ & $453.82 \pm 5.45$ \\
\hline KLE & $182.05 \pm 0.36^{\mathrm{d}}$ & $49.03 \pm 0.45^{\mathrm{a}}$ & $9.06 \pm 0.70^{a}$ & $305.54 \pm 1.49^{a}$ \\
\hline KLW & $143.05 \pm 0.07$ & $40.55^{\mathrm{a}}$ & $9.06 \pm 0.11^{\mathrm{a}}$ & $276.88 \pm 2.70$ \\
\hline KSM & $207.18 \pm 2.32$ & $48.50 \pm 1.37^{\mathrm{a}}$ & $8.26 \pm 0.30^{\mathrm{a}}$ & $313.13 \pm 5.46^{\mathrm{a}}$ \\
\hline $\mathrm{KSE}$ & $95.03 \pm 1.36^{\mathrm{c}}$ & $41.87 \pm 3.00^{a}$ & $14.33 \pm 0.57^{\mathrm{c}}$ & $212.29 \pm 0.87$ \\
\hline KSW & $63.29 \pm 1.05^{b}$ & $30.74 \pm 0.46^{b}$ & $20.26 \pm 0.92^{c}$ & $148.75 \pm 3.81$ \\
\hline
\end{tabular}

Results with the same letters in each column are not significant

$\mathrm{K}=$ Kingiodendron pinnatum $; \mathrm{H}=$ Humboldtia brunonis; AA - ascorbic acid; L - Leaf; $\mathrm{S}$ - Stem; M - Methanol; E - Ethyl acetate; W - Water 
showed the highest zone of inhibition against B. subtilis. Antimicrobial activities of the leaf samples were always higher than the stem samples (Table 2). Methanolic leaf and stem extracts of H.brunonis and methanolic leaf extract of $K$. pinnatum exhibited anticandidal activity on par with standard Nystatin but no activity was found against Aspergillus and Trichoderma.

The highest phenolic content of $360.68 \mathrm{mg}$ gallic acid equivalent/g was observed in the methanolic leaf extract of $K$. pinnatum and the lowest of $63.29 \mathrm{mg}$ gallic acid equivalent/g, in the water extract of stem. The methanol extract of $H$. brunonis leaf showed a phenolic content of $189.51 \mathrm{mg}$ gallic acid equivalent/g and the water extract of the stem showed a lower phenolic content of $32.58 \mathrm{mg}$ gallic acid equivalent/g. Flavonoid contents of 60.43 and $122.46 \mathrm{mg}$ quercetin equivalent/g were observed in the methanolic leaf extracts of $H$. brunonis and $K$. pinnatum, respectively. The $\mathrm{IC}_{50}$ values of 7.66 and $7.2 \mu \mathrm{g} / \mathrm{mL}$ for DPPH scavenging activity was observed in methanolic leaf extracts of $H$. brunonis and $K$. pinnatum, respectively. A significantly higher reducing power of $453.82 \mathrm{mg}$ AAE $/ \mathrm{g}$ for the methanolic leaf extract of $K$. pinnatum followed by $338.69 \mathrm{mg} \mathrm{AAE} / \mathrm{g}$ for the methanolic leaf extract of $H$. brunonis were observed in the present study (Table 3).

\section{DISCUSSION}

The current study revealed the presence of phenols, flavonoids, glycosides, tannins in all extracts of $H$. brunonis and $K$. pinnatum while alkaloids were not detected. In addition, the methanolic leaf extract of H. brunonis showed the presence of steroids, while the methanolic leaf extract of $K$. pinnatum showed the presence of saponin and resins.

Some authors have linked the presence of phytochemicals to the antimicrobial properties of plant extracts (Adekosan et al., 2007). Mariita et al. (2010) have reported a strong antimicrobial activity (zones of inhibition between 9.00 and $14.10 \mathrm{~mm}$ ) in Entada abysinnica Steudel ex A. Rich (Fabaceae) against C. albicans, S. typhi and S. aureus. The methanolic extract was reported to have a better zone of inhibition against C. albicans than fluconazole, whose zone of inhibition was $13.00 \mathrm{~mm}$ while no appreciable activity was reported against $E$. coli and $K$. pneumoniae. In the current study, the stem extracts of $H$. brunonis showed no activity against $E$. coli. It is suggested that the lack of appreciable activity of the plant extracts against $E$. coli may be due to the development of drug resistance through extendedspectrum $\beta$-lactamase production (Heffernan et al.,
2009). Dyamavvanahalli et al. (2011) reported that the ethyl acetate leaf extract of Humboldtia exhibited significant antibacterial activity against Gram positive and Gram negative bacteria but no activity was observed in the methanolic leaf extract. In the present study however, both extracts showed significant activity. This may be due to the varied susceptibility of different strains of bacteria as well as species differences in plants (Karou et al., 2006).

The high ability of phenolics to scavenge free radicals may be due to the presence of many phenolic hydroxyl groups (Sawa et al., 1999). In the present study, extracts with higher phenols and flavonoids showed a high antioxidant activity. Furthermore, the total phenolic content and flavonoids were significantly higher in the methanolic extracts compared to the aqueous and ethyl acetate extracts. DPPH assay reaction depends on the ability of the samples to scavenge free radicals, which is visually noticeable as the colour changes from purple to yellow due to the hydrogen donating ability. The more rapid the absorbance decrease, the more potent the primary antioxidant activity (Saumya \& Mahaboob, 2011). Methanolic extract of the leaves of $K$. pinnatum has been previously reported to have DPPH radical scavenging activity where the hydrogen donors scavenge free radical DPPH at a concentration of $0.01 \mathrm{mg} / \mathrm{mL}$ (Komal et al., 2011). In the present study, similar results were obtained. The $\mathrm{IC}_{50}$ of methanolic extract had a very high free radical scavenging activity in both plants.

In $H$. brunonis, there was no significant correlation between phenols and DPPH free radical scavenging activity $(\mathrm{r}=-0.8032, \mathrm{p}=0.0543)$ while a significant positive correlation was observed between phenols and the reducing power $(\mathrm{r}=0.9828, \mathrm{p}=0.0004)$. Flavonoids with DPPH free radical scavenging activity showed a significant negative correlation $(\mathrm{r}=-0.9310, \mathrm{p}=$ 0.007 ) and with reducing power, a significant positive correlation $(\mathrm{r}=0.8363, \mathrm{p}=0.038)$. Even in $K$. pinnatum, the correlation between phenols and DPPH free radical scavenging activity was not significant $(\mathrm{r}=-0.7757$, $\mathrm{p}=0.06$ ) whereas in the reducing power assay, it showed a significant positive correlation $(r=0.9845, p=0.0004)$. Flavonoids with DPPH free radical scavenging activity showed no significant correlation $(r=-0.5589, p=0.249)$ and with reducing power, a significant positive correlation $(\mathrm{r}=0.8924, \mathrm{p}=0.016)$. There was a positive linear correlation between the antioxidant activity and the total phenolic content in aqueous and methanolic extracts of selected Jordanian plant species (Tawaha et al., 2007). A significant negative correlation between the phenolics content and the DPPH antioxidant activity was observed in potato varieties, indicating the role of phenolics in 
radical scavenging activity (Hesam et al., 2012). The significant negative correlation observed between the flavonoids and the DPPH radical scavenging activity in the present study could be due to the presence of some of the active phenolic compounds in H. brunonis plant extract contributing towards scavenging of free radicals.

Methanolic leaf extract of both plants showed high phenolic compounds and reasonable antimicrobial and high antioxidant activities. There is scope to pursue as the antifungal activity of methanolic extract of Kingiodendron pinnatum, which showed better activity compared to standard Nystatin.

\section{Acknowledgement}

The authors gratefully acknowledge Department of Science and Technology, New Delhi for the financial support in the form of INSPIRE fellowship.

\section{REFERENCES}

1. Adesokan A.A., Akanji M.A. \& Yakubu M.T. (2007). Antibacterial potentials of aqueous extract of Enantia chlorantha stem bark. African Journal of Biotechnology 6(22): $2502-2505$.

2. Alviano D.S. \& Alviano C.S. (2009). Plant extracts: search for new alternatives to treat microbial diseases. Current Pharmaceutical Biotechnology 10: 106 - 121. DOI: http://dx.doi.org/10.2174/138920109787048607

3. Arumugasamy K. (2012). Antimicrobial properties of Exacum wightianum arn. (Gentianaceae) an endemic medicinal plant from the Western Ghats, Tamil Nadu. International Journal of Pharmaceutical Research and Development 4(05): $001-007$.

4. Arunachalam K. (2011). Antioxidant and antimicrobial potential of methanolic extract of Indian sacred grove Gymnostachyum febrifugum Benth. root. International Journal of Pharmaceutical and Biomedical Research 2(3): $67-71$.

5. Dyamavvanahalli L.S., Raveesha K.A. \& Nagabhushan (2011). Bioprospecting of selected medicinal plants for antibacterial activity against some pathogenic bacteria. Journal of Medicinal Plants Research 5(17): 4087 - 4093.

6. Dey P.M. \& Harborne J.B. (1987). Methods in Plant Biochemistry. Academic Press. London, UK.

7. Heffernan H.M., Woodhouse R.E., Pope C.E. \& Blackmore T.K. (2009). Prevalence and types of extendedspectrum beta-lactamases among urinary Escherichia coli and Klebsiella spp. in New Zealand. International Journal of Antimicrobial Agents 34: 544 - 549.

DOI: http://dx.doi.org/10.1016/j.ijantimicag.2009.07.014

8. Hesam F., Balali G.R. \& Tehrani R.T. (2012). Evaluation of antioxidant activity of three common potato (Solanum tuberosum) cultivars in Iran. Avicenna Journal of Phytomedicine 2: $79-85$.

9. Hidayathulla S., Chethankumar K.V. \& Chandrashekar
K.R. (2011). Phytochemical screening, in vitro antibacterial activity and identification of antibacterial components in leaf extracts of Sapium insigne (Royle) Benth. ex Hook.f. Journal of Pharmacy Research 4: 90 - 92.

10. Karou D., Savadogo A., Canini A., Yameogo S., Montesano C., Simpore J., Colizzi V. \& Traore A.S. (2006). Antibacterial activity of alkaloids from Sida acuta. African Journal of Biotechnology 5(2): $195-200$.

11. Komal K., Devi Prasad A.G. \& Richard S.A. (2011). Biochemical activity of endangered medicinal plant Kingiodendron pinnatum. Asian Journal of Plant Science and Research 1(4): $70-75$.

12. Liyana-Pathirana C.M. \& Shahidi F. (2005). Antioxidant activity of commercial soft and hard wheat (Triticum aestivum L.) as affected by gastric $\mathrm{pH}$ conditions. Journal of Agricultural Food Chemistry 53: 2433 - 2440.

13. Mariita R.M., Orodho J.A., Okemo P.O. \& Mbugua P.K. (2010). Antifungal, antibacterial and antimycobacterial activity of Entada abysinnica Steudel ex A. Rich (Fabaceae) methanol extract. Pharmacognosy Research 2(3): 163 168.

DOI: http://dx.doi.org/10.4103/0974-8490.65511

14. Nair V.D., Gopi R. \& Panneerselvam R. (2012). Isolation and structure elucidation of natural antioxidants from leaves of Rauvolfia beddomethe: an endemic/endangered medicinal plant from South Western Ghats of India. Pharmaceutical Chemistry Journal 46(1): 35 - 44. DOI: http://dx.doi.org/10.1007/s11094-012-0730-3

15. Okwu D.E. \& Josiah C. (2006). Evaluation of the chemical composition of two Nigerian medicinal plants. African Journal of Biotechnology 5(4): 357 - 361.

16. Oudhia P. \& Tripathi R.S. (1999). Scope of cultivation of important medicinal plants in Chhattisgarh plains. Proceedings of the National Conference on Health Care and Development of Herbal Medicines. Indira Gandhi Agricultural University, Raipur, India.

17. Oyaizu M. (1986). Studies on products of browning reaction: antioxidant activities of products of browning reaction prepared from glucosamine. Japanese Journal of Nutrition 44: $307-315$.

18. Pascal J.P. (1988). Wet Evergreen Forests of the Western Ghats of India: Ecology, Structure, Floristic Composition and Succession. Institute Francias De Pondicherry, Pondicherry, India.

19. Prusti A., Mishra S.R., Sahoo S. \& Mishra S.K. (2008). Antibacterial activity of some Indian medicinal plants. Ethnobotanical Leaflets 12: 227 - 230.

20. Saumya S.M. \& Mahaboob B.P. (2011). In vitro evaluation of free radical scavenging activities of Panax ginseng and Lagerstroemia speciosa: a comparative analysis. International Journal of Pharmacy and Pharmaceutical Sciences 3(1): $165-169$.

21. Sawa T., Nako M., Akaike T., Ono K. \& Maeda H. (1999). Alkylperoxyl radical scavenging activity of various flavonoids and other phenolics compounds: implementations for the antitumour promoter effect of vegetables. Journal of Agricultural Food Chemistry 47: $397-492$.

DOI: http://dx.doi.org/10.1021/jf980765e 
22. Shetty S., Vinayachandra, Hidayathulla S. \& Chandrashekar K.R. (2011). Antimicrobial activity and phytochemical Screening of Pterospermum reticulatum Wighty \& Arn. International Journal of Pharmacy and Pharmaceutical Sciences 3(5): $35-37$.

23. Sukesh, Hidayathulla S., Haneef M., Arunkumar K. \& Chandrashekar K.R. (2011). Phytochemical evaluation, antioxidant and antibacterial activity of seed wings of Hopea ponga (Dennst.) Mabberly. Journal of Pharmacy Research 4(8): 2593 - 2598.

24. Taga M.S., Miller E.E. \& Pratt D.E. (1984). Chia seeds as a source of natural lipid antioxidants. Journal of the American Oil Chemists' Society 61: 928 - 931. DOI: http://dx.doi.org/10.1007/BF02542169

25. Tawaha K., Alali F.S., Gharaibeh M., Mohammad M. \& El-Elimat T. (2007). Antioxidant activity and total phenolic content of selected Jordanian plant species. Food Chemistry 104: $1372-1378$.

DOI: http://dx.doi.org/10.1016/j.foodchem.2007.01.064
26. Vardar-Unlu G., Candan F., Sokemen A., Daferra D., Pollissiou M., Sokemen M., Donmez E. \& Tepe B. (2003). Antimicrobial and antioxidant activity of the essential oil and methanol extract of Thymus pectinatus. Journal of Agricultural and Food Chemistry 51(1): 61 - 67. DOI: http://dx.doi.org/10.1021/jf025753e

27. Wink M. (2003). Evolution of secondary metabolites from an ecological and molecular phylogenetic perspective. Phytochemistry 64: 3-19.

28. Wojciechowski M.F., Lavin M. \& Sanderson M.J. (2004). A phylogeny of legumes (Leguminosae) based on analyses of the plastid matK gene resolves many well-supported subclades within the family. American Journal of Botany 91: $1846-1862$. DOI: http://dx.doi.org/10.3732/ajb.91.11.1846

29. Zishen J., Mengcheng T. \& Jianming W. (1999). The determination of flavonoid contents in mulberry and their scavenging affects on superoxide radicals. Food Chemistry 64: $555-559$. 